\title{
LONG-TERM VOICE OUTCOMES AND QUALITY OF LIFE AFTER OPEN PARTIAL HORIZONTAL LARYNGECTOMY TYPE II VS TOTAL LARYNGECTOMY: A CROSS-SECTIONAL STUDY
}

\author{
Lucia D'Alatri ${ }^{1}$, Ylenia Longobardi ${ }^{1}$, Claudio Parrilla ${ }^{1}$, Fabrizio Crudo $^{2}$, Giuseppe \\ Oliveto $^{3}$, Giorgia Mari ${ }^{3}$, Maria Raffaella Marchese ${ }^{3}$, Giulio Cesare Passali ${ }^{3}$, Carolina Ausili \\ Cefaro $^{3}$, Gaetano Paludetti ${ }^{4}$, and Jacopo Galli ${ }^{3}$ \\ ${ }^{1}$ Universita Cattolica del Sacro Cuore Facolta di Medicina e Chirurgia \\ ${ }^{2}$ Università Cattolica del Sacro Cuore Facoltà di Medicina e Chirurgia \\ ${ }^{3}$ Policlinico Universitario Agostino Gemelli \\ ${ }^{4}$ Università Cattolica del Sacro Cuore
}

September 28, 2021

\begin{abstract}
Objectives: We aim to analyze long-term voice outcomes and Quality of Life (QoL) in patients undergoing Open Partial Horizontal Laryngectomy Type II (OPHL Type II) and to compare them to those obtained by patients undergoing Total Laryngectomy (TL) with voice prosthesis (VP). Design: Cross-sectional cohort study Setting: patients undergoing surgery for advanced laryngeal cancer, assessed during the usual follow-up consultations at the Phoniatric Unit (February 2020-December 2020). Participants: Forty-five patients were enrolled and divided into two groups: OPHL Group and TL Group. Main outcomes measures: Maximum phonation time, INFV0 scale, I-SECEL, UWQoL-V4 and MDADI questionnaires were used to assess the long-term outcomes. Results: Voices of patients undergoing OPHL Type II were worse than those of laryngectomized patients with VP. Nevertheless, scores in voice and dysphagia-related QoL were comparable and scores in the Social domain of QoL were better in OPHL group. Conclusions. OPHL Type II allows an acceptable voice recovery and a satisfactory QoL.
\end{abstract}

\section{Hosted file}

manuscript 2.0.docx available at https://authorea.com/users/438373/articles/539585-1ongterm-voice-outcomes-and-quality-of-life-after-open-partial-horizontal-laryngectomy-typeii-vs-total-laryngectomy-a-cross-sectional-study

\section{Hosted file}

Tables.docx available at https://authorea.com/users/438373/articles/539585-long-term-voiceoutcomes-and-quality-of-life-after-open-partial-horizontal-laryngectomy-type-ii-vstotal-laryngectomy-a-cross-sectional-study 